\title{
Preparation of Microcapsules Containing Triple Core Materials with Interfacial Condensation Reaction
}

\author{
Yoshinari Taguchi, Mikihiko Aoki, Masato Tanaka* \\ Graduate School of Science and Technology, Niigata University, Niigata, Japan \\ Email: *tanaka@eng.niigata-u.ac.jp
}

Received 12 June 2014; revised 15 July 2014; accepted 16 August 2014

Copyright (C) 2014 by authors and Scientific Research Publishing Inc.

This work is licensed under the Creative Commons Attribution International License (CC BY).

http://creativecommons.org/licenses/by/4.0/

(c) (†) Open Access

\begin{abstract}
In this manuscript, we describe the novel method for preparing the microcapsules containing $\alpha$-tocopherol oil droplets as the first core material, calcium chloride powder as the second core material and the fine water droplets as the third core material by the interfacial condensation reaction between hydroxyl propyl methyl cellulose and tannic acid. The interfacial condensation reaction was performed between hydroxyl propyl methyl cellulose dissolved in the continuous water phase and tannic acid dissolved in the inner fine water droplets as the third core material. The calcium chloride powder as the second core material was dispersed in the $\alpha$-tocopherol oil droplet as the first core material beforehand. The $\alpha$-tocopherol oil containing the second and the third core materials was dispersed in the continuous water phase to form the $[(S+W) / 0 / W]$ emulsion. The $\alpha$-tocopherol oil as the first core material was microencapsulated satisfactorily and the contents of the second core material were increased with the concentration of stearic acid as the oil soluble stabilizer. The mechanical strength of microcapsules increased with the concentration of hydroxyl propyl methyl cellulose. Thermal energy could be released by breaking the microcapsules in water and by dissolving calcium chloride in the continuous water phase.
\end{abstract}

\section{Keywords}

Triple Core Materials-Containing-Microcapsule, Multiple Emulsions, $\alpha$-Tocopherol, Calcium Chloride, Dissolution Heat, Hydroxy Propyl Methyl Cellulose, Tannic Acid

\section{Introduction}

Many kinds of microcapsules have been developed and utilized in the various fields such as cosmetics, food in${ }^{*}$ Corresponding author.

How to cite this paper: Taguchi, Y., Aoki, M. and Tanaka, M. (2014) Preparation of Microcapsules containing Triple Core Materials with Interfacial Condensation Reaction. Journal of Cosmetics, Dermatological Sciences and Applications, 4, 275283. http://dx.doi.org/10.4236/jcdsa.2014.44037 
dustry, drugs, paintings, adhesives and so on [1]-[4]. Selection of the shell materials of microcapsules depends on the desired functions such as thermal and $\mathrm{pH}$-responsibility, hydrophilicity, hydrophobicity, biodegradability and anti-solubility. It is necessary to develop the new preparation method suitable to these demands. Especially, when the microcapsules are used/utilized in the fields such as food, cosmetics and drug, the microcapsules must be prepared by using the nontoxic shell materials. Also, during microencapsulation of both hydrophobic and the hydrophilic core materials at the same time, it is necessary to develop the effective method for preparing microcapsules with the higher content of core materials. $\alpha$-tocopherol being an antioxidant, reduces risk of diseases such as cardiovascular diseases, and also $\alpha$-tocopherol has been used as supplement. So, if $\alpha$-tocopherol could be kept safely and released at occasion demands, it will be expected that $\alpha$-tocopherolcan be utilized in more fields.

$\mathrm{W}$. Somchue, et al. have microencapsulated $\alpha$-tocopherol with protein in order to use the microcapsules as the delivery particles [5]. Song, Y.B., et al. have tried to prepare the microcapsules containing $\alpha$-tocopherol with the gellatedpectin and established the optimum preparation conditions [6].

Furthermore, it is well known that calcium chloride is hygroscopic and has heat of dissolution of $285 \mathrm{~kJ} / \mathrm{kg}$. If heat of dissolution of calcium chloride is released gradually, its utilization can be expected. For an example, if this heat of dissolution of calcium chloride is gradually released on the face and body skin, it may be expected to keep the face and the body warm. Also, as water can dissolve different kinds of chemicals, various aqueous solutions could be microencapsulated well and the fine droplets containing the aqueous solution can be utilized as the reservoir of water and chemicals. The above stated aims may be accomplished by microencapsulating $\alpha$-tocopherol, the aqueous solution and the calcium chloride powder at the same time.

Authors have developed the preparation method for microencapsulating the eucalyptus oil with the interfacial condensation reaction between hydroxyl propyl methyl cellulose and tannic acid and established the optimum preparation conditions [7]. In the microencapsulation mechanism, authors describe the importance of tannic acid to transfer from the inner water droplets to the interface through the eucalyptus oil phase and subsequent reaction with hydroxyl propyl methyl cellulose. In this study, $\alpha$-tocopherol was used instead of eucalyptus oil and it was tried to microencapsulate the triple core materials and at the same time the microencapsulation mechanism is presented.

The purpose of this study is to investigate whether the $\alpha$-tocopherol oil, the aqueous solution and the calcium chloride powder can be microencapsulated at the same time, and to characterize the microcapsules and to discuss the possible microencapsulation mechanism based on the result obtained.

\title{
2. Experimental
}

\subsection{Materials}

Materials used to prepare the microcapsules containing $\alpha$-tocopherol, the fine water droplets and the solid powder of $\mathrm{CaCl}_{2}$ were as follows.

\subsubsection{Shell Material}

Hydroxyl propyl methyl cellulose (HPMC) (Shinetsu Kagaku Kogyo, Co. Ltd.)

Tannic acid (TA) (Tokyo Kasei, Co. Ltd.)

\author{
2.1.2. Core Materials \\ $\alpha$-tocopherol ( $\alpha$-oil) (Kanto Chemical, Co. Ltd.) \\ Calcium Chloride $\left(\mathrm{CaCl}_{2}\right.$, Kanto Chemical, Co. Ltd.) \\ Aqueous solution of tannic acid.
}

\subsubsection{Oil Soluble Stabilizer and Surfactant}

Stearic acid (ST) (Kanto Chemical, Co. Ltd.)

Soybean Lecithin (LC) (Junsei Chemical, Co. Ltd.)

\subsection{Preparation of Microcapsules}

The microcapsules were prepared by modification of the reported methods [7]. Figure 1 shows the flow sheet for preparing the microcapsules containing the triple core materials together with the schematic diagrams of mi- 


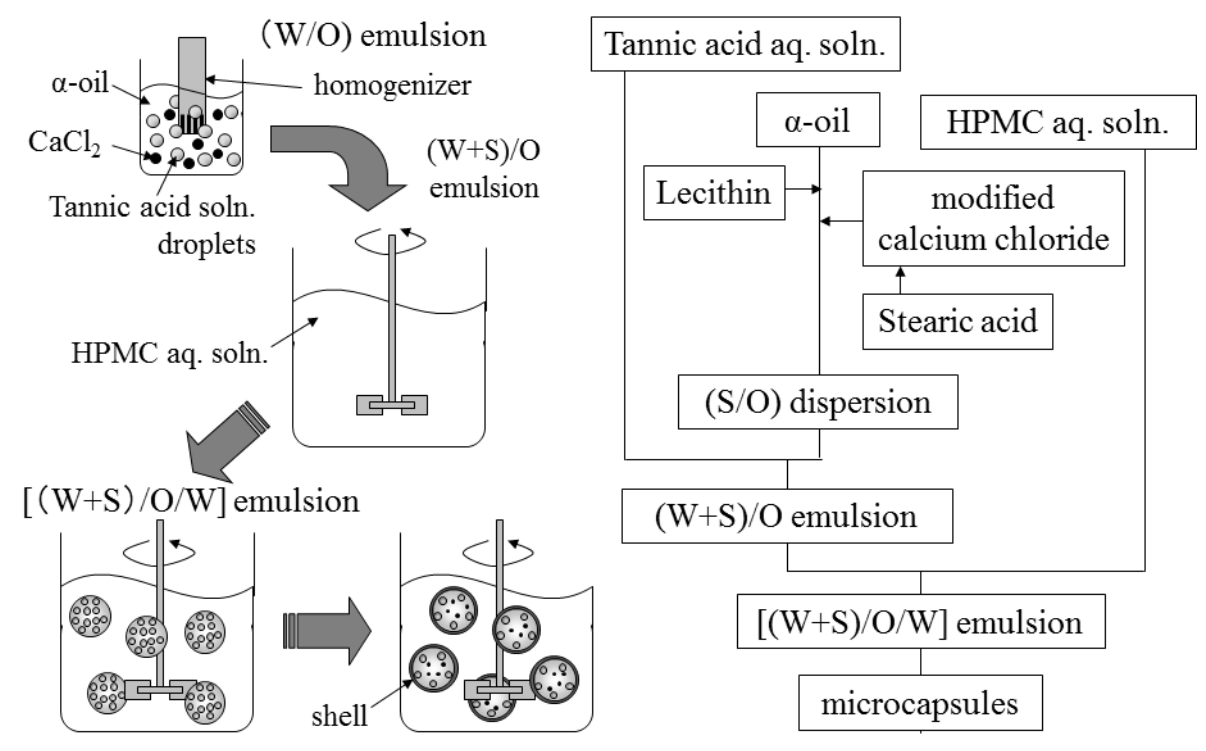

Figure 1. Flow chart for preparing microcapsules.

croencapsulation process. $\alpha$-tocopherol ( $\alpha$-oil) dissolving soybean lecithin (LC) as an oil soluble surfactant was prepared as the first core material. Tannic acid (TA) aqueous solution was dispersed in $\alpha$-tocopherol ( $\alpha$-oil) to form the fine aqueous droplets as the second core material. Here, it is necessary for tannic acid (TA) dissolved in the inner aqueous droplets to transfer through $\alpha$-tocopherol ( $\alpha$-oil), to react with HPMC and to form the microcapsule shell. The calcium chloride powder as the third core material was prepared by the following two methods.

First, the calcium chloride powder was modified by mixing with stearic acid as an oil soluble stabilizer to provide hydrophobicity and added to $\alpha$-tocopherol $(\alpha$-oil) to form the (S/O) dispersion. Hereafter, this preparation method will be called the modification method. Second, the calcium chloride powder was dissolved in distilled water. This aqueous solution was added into $\alpha$-tocopherol $(\alpha$-oil) and stirred to form the (W/O) emulsion. Then, the $(\mathrm{W} / \mathrm{O})$ emulsion was dried under reduced pressure and $70^{\circ} \mathrm{C}$ to remove the water and to form the $(\mathrm{S} / \mathrm{O})$ dispersion where finer calcium chloride powder was dispersed in $\alpha$-tocopherol ( $\alpha$-oil) dissolving stearic acid. Hereafter, this preparation method will be called the breakdown method. The $(\mathrm{S} / \mathrm{O})$ dispersion thus prepared was added into the $(\mathrm{W} / \mathrm{O})$ emulsion to form $[(\mathrm{W}+\mathrm{S}) / \mathrm{O}]$ emulsion. The $[(\mathrm{W}+\mathrm{S}) / \mathrm{O}]$ emulsion was poured into the HPMC aqueous solution and stirred to form the $[(\mathrm{W}+\mathrm{S}) / \mathrm{O} / \mathrm{W}]$ emulsion. Then, temperature of the $[(\mathrm{W}+\mathrm{S}) /$ $\mathrm{O} / \mathrm{W}$ ] emulsion was raised to $40^{\circ} \mathrm{C}$ to perform the interfacial condensation reaction between HPMC and tannic acid (TA). It may be expected that tannic acid (TA) may transfer through $\alpha$-tocopherol ( $\alpha$-oil) from the inner water droplets to the interface between $\alpha$-tocopherol ( $\alpha$-oil) and the continuous water phase and react with HPMC. In this fundamental experiment, the concentrations of HPMC and stearic acid (ST) were changed. The experimental conditions are shown in Table 1.

\subsection{Characterization}

\subsubsection{Observation of Microcapsules}

It was observed whether the microcapsules could be prepared or not as follows. Namely, after preparing the microcapsules, the $(\mathrm{S}+\mathrm{W}) / \mathrm{O} / \mathrm{W}$ emulsion was set and observed by visual confirmation. If the microcapsules are not be prepared well, the multiple emulsion can be broken rapidly.

Then, the microcapsules were observed by optical microscope and scanning electron microscope (SEM). The shape and inner structure of microcapsule were observed from these photographs and the effects of experimental conditions on them were discussed.

\subsubsection{Diameter Distribution}

The diameter distributions and mean diameters of microcapsules were obtained directly from the photographs taken by the optical microscope. Here, the mean diameters of microcapsules are the mean Sauter diameters. 
Table 1. Experimental conditions.

\begin{tabular}{cc}
\hline Distilled water & $270 \mathrm{ml}$ \\
HPMC conc. & $0.05 \sim 0.2 \mathrm{wt} \%$ \\
$\alpha$-oil & $27 \mathrm{ml}$ \\
Calcium chloride & $1 \mathrm{~g}$ \\
Stearic acid conc. & $0.1 \sim 1.0 \mathrm{wt} \%$ oil \\
Lecithin conc. & $3 \mathrm{ml}(0.1 \mathrm{wt} \%$ oil $)$ \\
Tannic acid soln. & $3 \mathrm{ml}(0.2 \mathrm{~mol})$ \\
Revolution speed to form (W/O) emulsion & $3000 \mathrm{rpm}$ \\
Revolution time & $10 \mathrm{~min}$ \\
Reaction temperature & $40^{\circ} \mathrm{C}$ \\
Reaction time & $1 \mathrm{~h}$ \\
Revolution speed to form [(S + W)/O/W] & $300 \mathrm{rpm}$ \\
Emulsion and to prepare microcapsules &
\end{tabular}

\subsubsection{Mechanical Strength of Microcapsules}

The mechanical strength of microcapsules was measured by the hardening measurement instrument (Shimazu Seisakusho, Japan, MCT-W500).

\subsubsection{Microencapsulation Efficiency of Calcium Chloride Powder}

The microcapsules of given weight were added in distilled water of 5cc and broken by mechanical pressure to measure temperature of water in the adiabatic vessel. The temperature rise degree was compared with the calibration curve between the calcium chloride concentration and the temperature rise degree. The weight of calcium chloride microencapsulated was obtained from this result. The microencapsulation efficiency $(\mathrm{Y})$ was estimated from the following Equation (1).

$$
Y=\frac{\text { weight of calcium chloride microencapsulated }}{\text { weight of calcium chloride in feed }}
$$

\section{Results \& Discussion}

\subsection{Confirmation of Microcapsule Formation}

In order to confirm whether the microcapsules could be prepared or not according to the microencapsulation mechanism presented in the previous study [7], first, the stability of (W/O)/W emulsion before and after the microencapsulation process without addition of calcium chloride powder was investigated by visual confirmation.

Figure 2 shows the photographs of the (W/O)/W emulsion without and with the microencapsulation process. These photographs were taken at just after formation of the (W/O)/W emulsion, after $30 \mathrm{~s}$ and after 7 days, respectively. In the case of the (W/O)/W emulsion without the microencapsulation process, the $(\mathrm{W} / \mathrm{O}) / \mathrm{W}$ emulsion was formed just after emulsification, however, the (W/O)/W emulsion was broken and the phase separation occurred after $30 \mathrm{~s}$ as shown in Figure 2(a). However, in the case of the (W/O)/W emulsion with the microencapsulation process, the (W/O)/W emulsion was formed just after emulsification and kept after $30 \mathrm{~s}$ and 7 days as shown in Figure 2(b). Furthermore, the formation of microcapsules could be confirmed by the photograph inserted in Figure 2(b).

Also, the optical microscopic photographs of microcapsules prepared at $\mathrm{C}_{\mathrm{HPMC}}=0.05 \mathrm{wt} \%$ and $\mathrm{C}_{\mathrm{HPMC}}=0.2$ wt $\%$ were shown in Figure 3. The microcapsules could be prepared at both the highest and the lowest concentrations of HPMC in this experiment.

From Figure 2 and Figure 3, it was found that tannic acid (TA) transferred from the inner water droplets to the interface through $\alpha$-tocopherol ( $\alpha$-oil) and reacted with hydroxyl propyl methyl cellulose (HPMC) and the inner aqueous droplets could be microencapsulated well as well as the eucalyptus oil [7].

Figure 4 shows the dependences of mechanical strength $\left(S_{t}\right)$ and mean diameters $\left(d_{p}\right)$ of microcapsules on the HPMC concentration $\left(\mathrm{C}_{\mathrm{HPMC}}\right)$. The mechanical strength increased with the HPMC concentration and become almost constant at the HPMC concentration larger than $\mathrm{C}_{\mathrm{HPMC}}=0.15 \mathrm{wt} \%$. The mean diameters increased from 
(a) without microencapsulation process
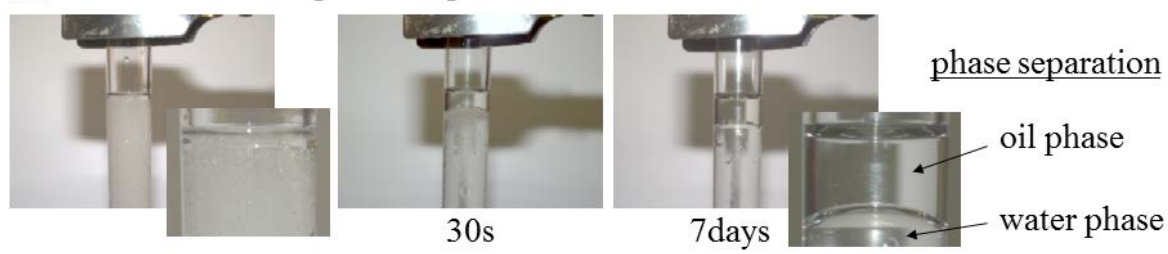

(b) with microencapsulation process
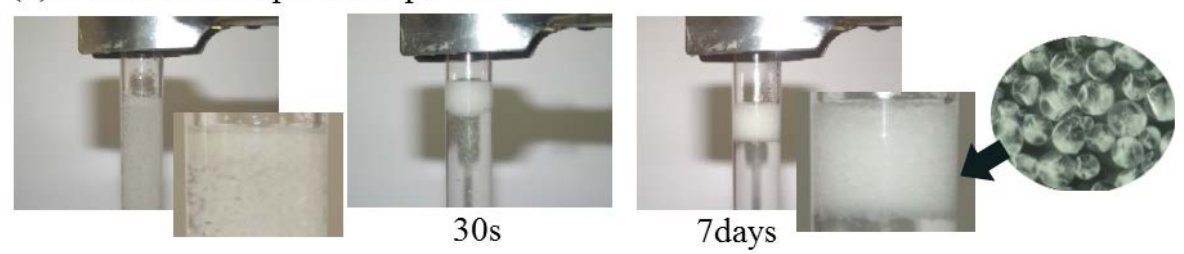

Figure 2. Transient features of [(W/O)/W] emulsion.
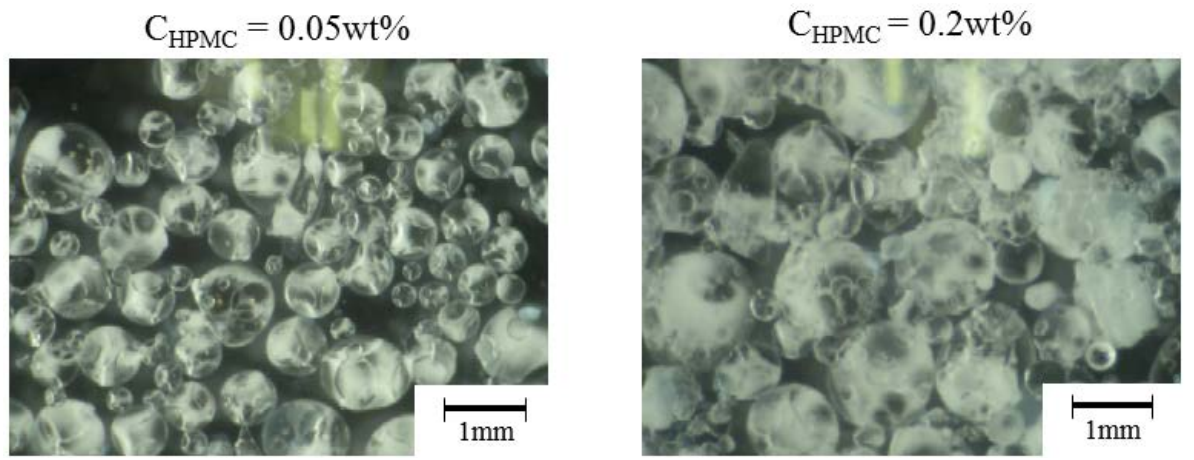

Figure 3. Optical microscopic photographs of microcapsules.

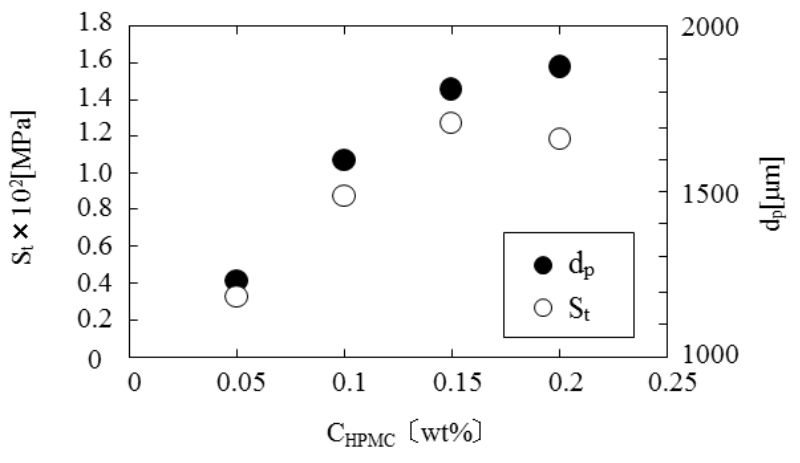

Figure 4. Mechanical strength of microcapsules.

$1200 \mu \mathrm{m}$ at $\mathrm{C}_{\mathrm{HPMC}}=0.05 \mathrm{wt} \%$ to $1900 \mu \mathrm{m}$ at $\mathrm{C}_{\mathrm{HPMC}}=0.2 \mathrm{wt} \%$. Hereafter, the microcapsules were prepared at $\mathrm{C}_{\mathrm{HPMC}}=0.2 \mathrm{wt} \%$ in order to microencapsulate the calcium chloride powder.

\subsection{Confirmation of Formation of Microcapsules Containing Calcium Chloride Powder}

In the preparation of desired microcapsules, the $(\mathrm{S} / \mathrm{O})$ dispersion was added to the $(\mathrm{W} / \mathrm{O})$ emulsion prepared beforehand to form the $[(\mathrm{W}+\mathrm{S}) / \mathrm{O} / \mathrm{W}]$ emulsion.

Figure 5 shows the optical microscopic photographs of microcapsules containing the calcium chloride powder at $\mathrm{C}_{\mathrm{HPMC}}=0.2 \mathrm{wt} \%$ and $\mathrm{C}_{\mathrm{ST}}=0.4 \mathrm{wt} \%$. It was found that the microcapsules could be prepared well and were filled with the calcium chloride powder. The microcapsules are opaque because of dispersion of calcium chlo- 


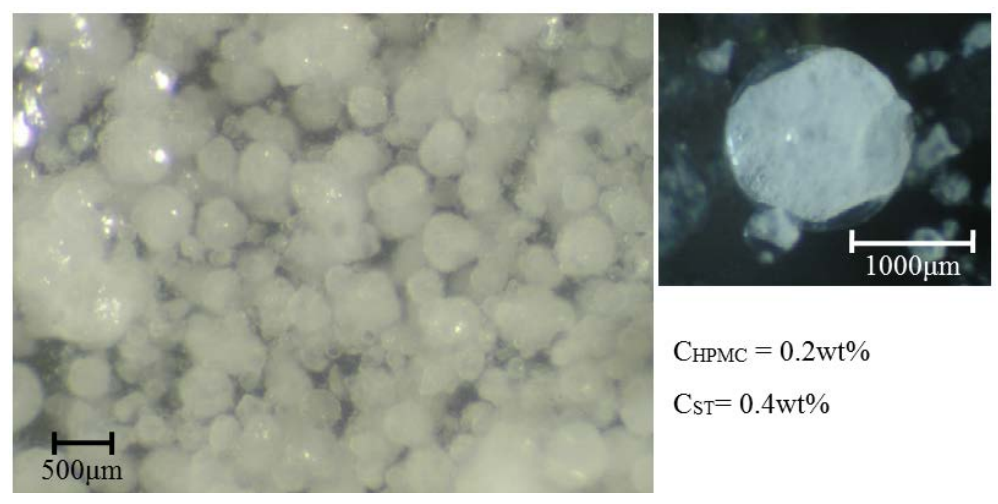

Figure 5. Photographs of microcapsules containing triple cores.

ride powder.

From Figures 2-5, the microcapsules containing $\alpha$-tocopherol ( $\alpha$-oil) as the first core, the calcium chloride powder as the second core and the aqueous droplets as the third core could be prepared well.

\subsection{Dependence of Microencapsulation Efficiency on ST Concentration and Formation Method of Calcium Chloride Powder}

Microencapsulation of solid powder has been mainly performed by selecting the oil soluble surfactant species [8] [9] and by modifying the surface of solid powder due to various coupling agents [10]-[12] in order to obtain the higher content possible.

Here, it was tried to investigate the effect of ST concentration and the (S/O) dispersion preparation method on the content of calcium chloride powder. In this experiment, the calcium chloride powder was modified to become hydrophobic by stearic acid beforehand (modification method) and to finer powder by breaking down the aqueous solution of calcium chloride into finer aqueous droplets and by removing water (break down method).

Figure 6 shows the dependence of microencapsulation efficiency on the ST concentration for the two preparation methods. It was found that the microencapsulation efficiency for the modification method increased from $8 \%$ to $55 \%$ with the highest ST concentration. However, the microencapsulation efficiency for the breakdown method increased from $8 \%$ to ca. $98 \%$. This result is considered to be due to the fact that calcium chloride powder become more finer and more stable in $\alpha$-tocopherol ( $\alpha$-oil).

\subsection{Rise in Temperature Due to Breakup of Microcapsules}

When the calcium chloride powder is released from the microcapsules into the water phase, temperature of aqueous solution may raise due to heat of dissolution of calcium chloride.

Figure 7 shows the rise in temperature of water phase by dissolving calcium chloride. In Figure 7, temperature of the water phase where the microcapsules of a given weight were broken by the finger pressure was plotted, too. It was found that the plots of temperature of the water phase coincided with the correlation plots between temperature of the water phase and the calcium chloride concentration.

From these results, it was confirmed that temperature of the water phase could be raised by breaking the microcapsules of amount designed beforehand.

Figure 8 shows the microcapsules dried under the room temperature. It was confirmed that the dried microcapsules could be safety kept within twenty days. The microcapsules can be used as the powder material containing the triple core materials.

\subsection{Microencapsulation Mechanism}

The microcapsules containing the triple core materials could be prepared well by the same preparation method as in the previous study. The microencapsulation mechanism may be discussed on the basis of the results obtained above.

Figure 9 shows the microencapsulation mechanism. The calcium chloride powder as the second core and the 


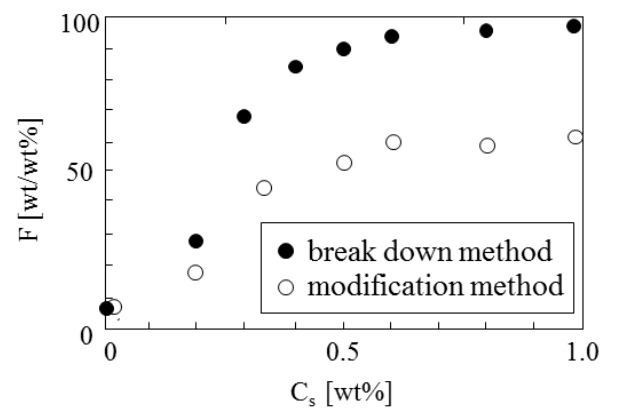

Figure 6. Dependence of microencapsulation efficiency of solid powder on ST concentration and preparation method.

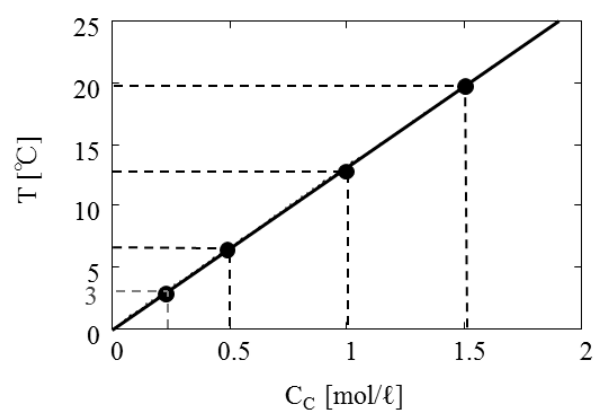

Figure 7. Dependence of temperature on calcium chloride concentration.

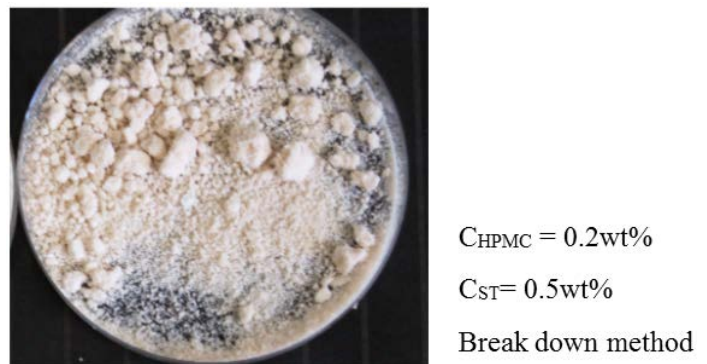

Figure 8. Optical photographs of dried microcapsules.

fine tannic acid (TA) aqueous droplets as the third core were stabilized and dispersed well in the $\alpha$-tocopherol ( $\alpha$-oil) droplets as the first core with the help of stearic acid (ST) and lecithin (LC), respectively as shown in Figure 9(b). Tannic acid (TA) dissolved in the inner water droplets should transfer to the interface between $\alpha$-tocopherol ( $\alpha$-oil) and the continuous water phase dissolving HPMC through the $\alpha$-tocopherol ( $\alpha$-oil) phase and then, reacted with HPMC to form the gelled HPMC shell. The contents of the second and the third core can be considerably increased by decreasing the diameters of inner water droplets and calcium chloride powder and by the stabilizing effect due to the adsorption of lecithin (LC) and stearic acid (ST) on the surface of the aqueous droplets and calcium chloride powder as shown in Figure 9(b). Accordingly, the break down method of calcium chloride powder was very useful to increase the content. Three core materials having the different physical property could be microencapsulated at the same time.

\section{Conclusions}

It was tried to prepare the microcapsules containing the triple core materials with the interfacial condensation reaction between hydroxyl propyl methyl cellulose and tannic acid. The following results were obtained.

1) The $\alpha$-tocopherol oil as the first core, the aqueous droplets as the second core and calcium chloride as the third core could be microencapsulated well at the same time by the microencapsulation mechanism presented in 
(a) HPMC aq. soln.

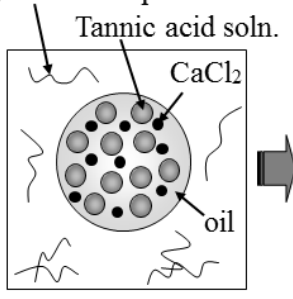

(W/O/W) emulsion

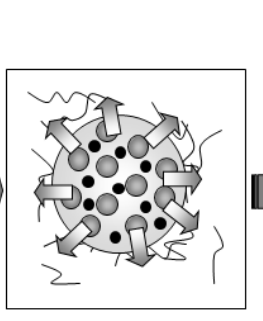

mass transfer

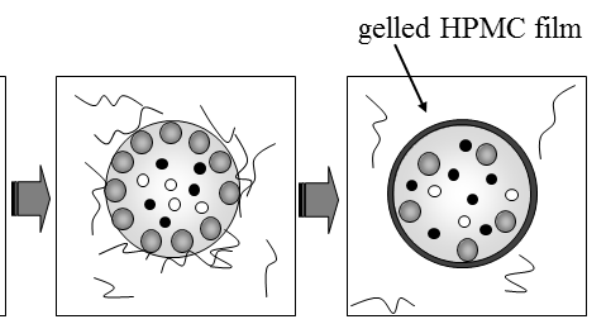

condensation reaction between HPMC and

Tannic acid (b)

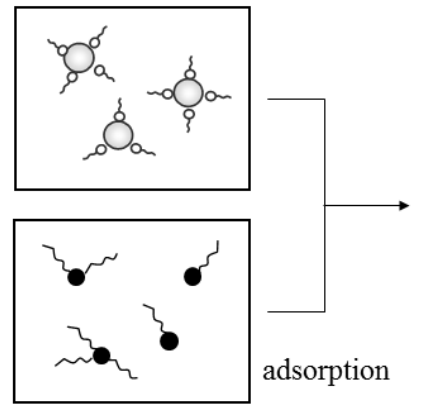

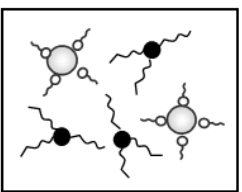

stabilization an Lecithin

Tannic acid aqueous droplet

- $\mathrm{CaCl}_{2}$

$\sim$ Stearic acid

Figure 9. Microencapsulation mechanism.

the previous study;

2) The mechanical strength of microcapsules increased with the HPMC concentration;

3) Microencapsulation efficiency of calcium chloride powder could be increased to ca. $98 \%$ with the breakdown method as the preparation method of calcium chloride powder;

4) The microcapsules were easily broken by the finger pressure and the calcium chloride powder could be released;

5) Temperature in the water phase was raised to temperature corresponding to the amount of calcium chloride microencapsulated;

6) It may be expected that the microcapsules can be utilized as the face and body cream.

\section{References}

[1] Kondo, T. and Tanaka, M. (1975) Microcapsules (Preparation, Properties, Application). Sankyo Shuppan, Tokyo.

[2] Kondo, T. (1967) Saishin Maikurokapseruka Gijutsu (Microencapsulation Technique). TES, Tokyo.

[3] Tanaka, M. (2008) Key Point of Preparation of Nano/Microcapsules. Techno System Publishing Co. Ltd., Tokyo.

[4] Koishi, M., Eto, K. and Higure, H. (2005) (Preparation + Utilization) Microcapsules. Kogyo Chosakai, Tokyo.

[5] Somchue, W., Sermsri, W., Shiowatana, J. and Siripinyanond, A. (2009) Encapsulation of $\alpha$-Tocopherol in ProteinBased Delivery Particles. Food Research International, 42, 909-914. http://dx.doi.org/10.1016/j.foodres.2009.04.021

[6] Song, Y.B., Lee, J.S. and Lee, H.G. (2009) $\alpha$-Tocopherol-Loaded Ca-Pectinate Microcapsules: Optimization, in Vitro Release, and Bioavailability. Colloids and Surfaces B: Biointerfaces, 73, 394-398. http://dx.doi.org/10.1016/j.colsurfb.2009.06.014

[7] Sato, H., Taguchi, Y. and Tanaka, M. (2014) Development of Preparation Method for Microencapsulating Uycalyptus Oil Containing Fine Aqueous Droplets by Use of Interfacial Condensation Reaction between Hydroxy Propyl Methyl Cellulose and Tannic Acid. Journal of Cosmetics, Dermatological Sciences and Applications, 4, 219-227. http://dx.doi.org/10.4236/jcdsa.2014.44030

[8] Costoyas, Á., Ramos, J. and Forcada, J. (2009) Encapsulation of Silica Nanoparticles by Miniemulsion Polymerization. Journal of Polymer Science: Part A: Polymer Chemistry, 47, 935-948. http://dx.doi.org/10.1002/pola.23212

[9] Slobodian, P., Pavlínek, V., Lengálová, A. and Sáha, P. (2009) Polystyrene/Multi-Wall Carbon Nanotube Composites Prepared by Suspension Polymerization and Their Electrorheological Behavior. Current Applied Physics, 9, $184-188$. http://dx.doi.org/10.1016/j.cap.2008.01.008

[10] Takahashi, M., Taguchi, Y. and Tanaka, M. (2009) Microencapsulation of Hydrophilic Solid Powder as a Fire Retar- 
dant by the Method of in Situ Gelation in Droplets Using a Non-Aqueous Solvent as the Continuous Phase. Polymers \& Polymer Composites, 17, 83-90.

[11] Takahashi, M., Taguchi, Y. and Tanaka, M. (2010) Microencapsulation of Hydrophilic Solidpowder as a Flame Retardant with Epoxyresin by Using Interfacial Reaction Method. Polymers for Advanced Technologies, 21, $224-228$.

[12] Sawatari, N., Fukuda, M., Taguchi, Y. and Tanaka, M. (2004) The Effect of Surface Treatment of Magnetite Powder on a Structure of Composite Particles Prepared by Suspension Polymerization. Journal of Chemical Engineering of Japan, 37, 731-736. http://dx.doi.org/10.1252/jcej.37.731 
Scientific Research Publishing (SCIRP) is one of the largest Open Access journal publishers. It is currently publishing more than 200 open access, online, peer-reviewed journals covering a wide range of academic disciplines. SCIRP serves the worldwide academic communities and contributes to the progress and application of science with its publication.

Other selected journals from SCIRP are listed as below. Submit your manuscript to us via either submit@scirp.org or Online Submission Portal.
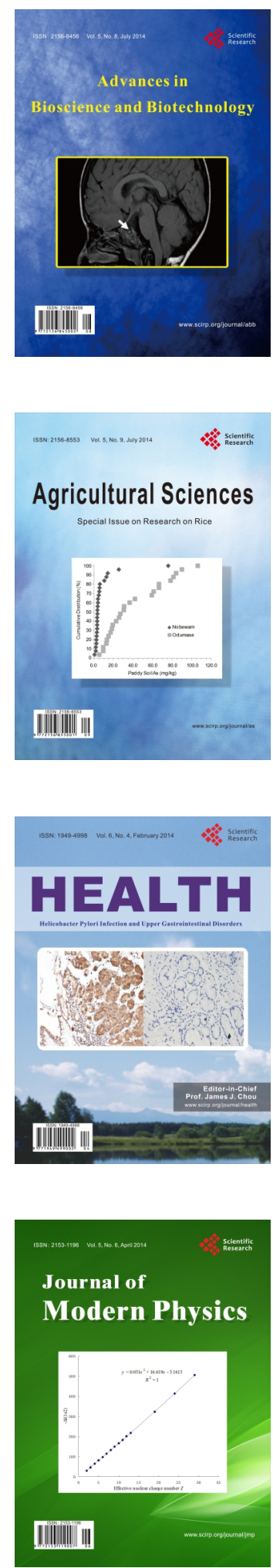
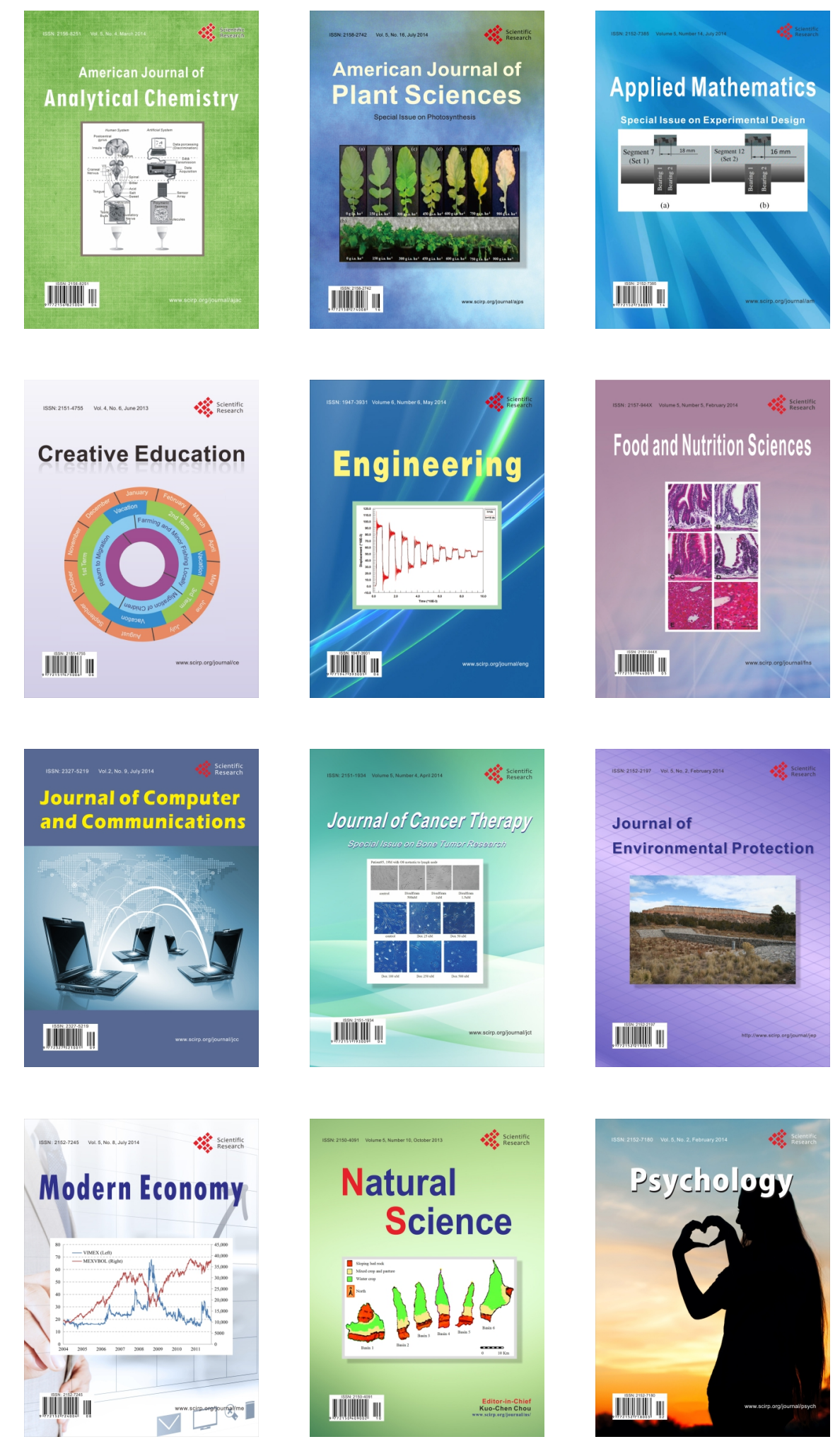